\title{
1 Industrial metal pollution in water and probabilistic assessment of human
}

\section{2 health risk}

3 Narottam Saha ${ }^{a^{*}}$, M. Safiur Rahman ${ }^{\mathrm{b}}$, Mohammad Boshir Ahmed ${ }^{\mathrm{c}}$, John L Zhou ${ }^{\mathrm{c}}$, Huu Hao

$4 \quad \mathrm{Ngo}^{\mathrm{c}^{*}}$, Wenshan $\mathrm{Guo}^{\mathrm{c}}$

5 aSchool of Earth Sciences, The University of Queensland, St Lucia, QLD 4072, Australia.

$6 \quad{ }^{b}$ Environmental Analytical Chemistry Laboratory, Institute of Nuclear Science and Technology, Bangladesh

7 Atomic Energy Commission, GPO Box 3787, Dhaka 1000, Bangladesh.

$8{ }^{\mathrm{c}}$ School of Civil and Environmental Engineering, University of Technology Sydney, Broadway, NSW 2007, $9 \quad$ Australia.

*Corresponding Authors:

21 ngohuuhao121@gmail.com or h.ngo@uts.edu.au (H. H. Ngo) narottam.saha@yahoo.com (N. Saha) 


\section{Abstract}

24 Concentration of eight heavy metals in the-surface and groundwater around Dhaka Export

25 Processing Zone (DEPZ) industrial area were investigated, and estimated the health risk of

26 theposed to-_local children and adult residents was determined-via ingestion and dermal

27 contact was evaluated using deterministic and probabilistic approaches. Metal concentrations

28 (except $\mathrm{Cu}, \mathrm{Mn}, \mathrm{Ni}$, and $\mathrm{Zn}$ ) in Bangshi River water were above the drinking water quality

29 guidelines, while in groundwater were less than the recommended limits. Concentration of metals in surface water decreased as a function of distance. These eEstimations of noncarcinogenic health risk for surface water revealed that mean hazard index (HI) values of As, $\mathrm{Cr}, \mathrm{Cu}$, and $\mathrm{Pb}$ for combined pathways (i.e., ingestion and dermal contact) were $>1.0$ for both age groups. The estimated risk mainly came from the ingestion pathway. However, the HI values for all the examined metals in groundwater were $<1.0$, indicating no possible human health hazard. Deterministically estimated total cancer risk (TCR) via Bangshi River water exceeded the acceptable limit of $1 \times 10^{-4}$ for adult and children. Although probabilistically estimated 95 th percentile values of TCR exceeded the benchmark, mean

38 TCR values assessed by Monte Carlo simulation-were less than $1 \times 10^{-4}$. Simulated results showed that $20.13 \%$ and $5.43 \%$ values of TCR for surface water were $>1 \times 10^{-4}$ for adult and children, respectively. Deterministic and probabilistic estimations of cancer risk through exposure to groundwater wereas well below the safety limit. Overall, the population exposed to Bangshi River water remained at carcinogenic and non-carcinogenic health threat and the risk was higher for adults. Sensitivity analysis identified exposure duration (ED) and ingestion rate (IR) of water were-as the most relevant variables affecting the probabilistic risk estimation model outcome.

46 Keywords: Water pollution; health risk analysis; deterministic approach; probabilistic approach; Monte-Carlo simulation. 


\section{Introduction}

Due to bioaccumulation capacity and persistence nature, heavy metals are considered as priority pollutants among a large amount of toxic substances released into water through human activates (Mainali et al., 2013). Although some heavy metals (e.g., $\mathrm{Cu}, \mathrm{Mn}$ and $\mathrm{Cr}$ ) are essential for human, their presence in excess amount may be toxic (Armendáriz et al., 2015; Espín et al., 2014). On the contrary, some metals (e.g., As, $\mathrm{Hg}, \mathrm{Cd}$ and Pb) are highly toxic at very low concentration with no known benefit for human health (Kavcar et al., 2009; Saha and Zaman, 2013). When entering enter into the environment, these metals can disrupt not only the aquatic ecosystem but also the human health (Quandt et al., 2010; Saha et al., 2016).

Analysis of heavy metal distribution in water is useful to trace the degree of water contamination induced by anthropogenic pressure (Alves et al., 2014). Recently, estimation of potential human health risk associated with the exposure to contaminated water has become a largely applied practice (Alves et al., 2014; Amaya et al., 2013; Wyatt et al., 1998). The traditional deterministic (point) approach in human health risk analysis through exposure to heavy metals using US Environmental Protection Agency (USEPA) guidance is straightforward, involving the application of simple formulas (USEPA, 1996). Deterministic risk analysis is based on assigning a single representative value to each input parameter in risk equation, which leads to an output of single value of risk (Zeng et al., 2009; Li and Zhang, 2010; Giri and Sing, 2015). The implementation of this conservative deterministic method in risk calculation is complicated due to the fact that the input parameters cannot be treated as fixed point values. Instead, the value of each parameter varies within a range. Assignment of multiple values for each input parameter in risk equation results in multiple estimates of risk. In order to address this complication and logical refinement in the practice of human health risk assessment, probabilistic approach has recently become popular and has 
been broadly applied in environmental science (Jiang et al., 2015; Kavcar et al., 2009; Qu et al., 2012). Probabilistic risk analysis combines the probability distributions (based on stochastic methods such as Monte Carlo simulation) of several input parameters in risk equation to estimate the probability distribution of output risk. Thus, the probabilistic approach may provide more accurate description than the traditional point estimate approach through the curve of probability density function (PDF), which evaluates intervals of possible values of the risk, each one with a specified probability ( Kavcar et al., 2009; RiveraVelasquez et al., 2013; Koupaie and Eskicioglu, 2015).

\section{Industrial pollution of Mother Nature has become a matter of great concern} worldwide, most notably for the under developed countries like Bangladesh. The present study area $\left(23^{\circ} 56^{\prime} 54.03^{\prime \prime N}\right.$ and $\left.90^{\circ} 16^{\prime} 22.55^{\prime \prime E}\right)$, Dhamsona Union under Savar sub-district is located $\sim 30 \mathrm{~km}$ north of Dhaka city (capital of Bangladesh) and the fastest growing industrial area surrounded by numerous industries including dyeing, textile, leather goods, metal products, chemical, fertilizers and so on. This industrial area comprises of two export processing zones (EPZ) called Dhaka Export Processing Zone 1 and 2 (DEPZ 1 and DEPZ 2)

(Fig. 1). The national highway from Dhaka to the northern part of Bangladesh is running between these two EPZ's. The untreated wastewater from industrial sites is discharged into the Dhalaibeel (a natural lake) and eventually follows its way to the downstream of Bangshi River (Fig. 1). The topography of the studied area comprises irregular elevated land blocks on which people live and surrounding low-laying area which is mostly cultivable lands and water bodies. The rural population_also usesonce used Bangshi River water for drinking purposes by simply boiling it and now government sets policy for not to use surface water $\underline{\text { without purification. }}$. Contaminated water from the Dhalaibeel and Bangshi River are mainly used to irrigate crops (mainly rice and various types of vegetables) in adjoining agricultural areas. This results in The industrial heavy metals contained in wastewater are transferred 
98 transfer of heavy metals to soils and eventually enter to the human body via food chain.

99 Moreover, these heavy metals have the potential to contaminate groundwater by leaching.

100 Strongly sorbed metals are likely to either remain near surface soil or transport to a stream via

101 runoff. On the other hand, weakly sorbed but persistent heavy metals may readily leach

102 through soil and contaminate groundwater that is mainly used for drinking purpose (Sponza

103 and Karaoğlu, 2002).

$104 \quad$ Adverse impact of economic and industrial growth on the environment has become a

105 prime concern for global populations and policy makers. Although the expansion of labor-

106 intensive export industries in the present study region is promoting the employment and per

107 capita income of thousands of population, this rapid industrial growth can also accelerate the

108 release of heavy metals and other chemical toxins into the environment and the rate of is

109 suffering enormous environmental degradation owing to industrialization environmental

110 degradation, with sever health hazards. Reliable heavy metals data in surface and

111 groundwater adjoin to the industries are critical to investigate the impact of industrial

112 pollution on health of different age groups (e.g., adult and children)., the assessment of

113 health hazard related to adult and children exposure to surface and groundwater around

114 DEPZ industrial zone is searee-Regardless, Mostefforts to investigateions on the DEPZ

115 industrial pollution have been focused mostly on determining levels of metals in

116 environmental matrices (e.g., soil, sediment, and foodstuff) and possible sources without

117 providing detailed information on human health risk derived from heavy metals in water

118 (Ahmed et al., 2012b; Islam et al., 2015; Rahman et al., 2012a; Rahman et al., 2014; Rahman

119 et al., 2012b). Thus, the aims of this study were to understand the spatial variability of heavy

120 metal concentration (such as $\mathrm{As}, \mathrm{Cd}, \mathrm{Cr}, \mathrm{Cu}, \mathrm{Mn}, \mathrm{Ni}, \mathrm{Pb}$, and $\mathrm{Zn}$ ) in surface water from the

121 industries, to characterize the groundwater quality around DEPZ, and to determine the 
exposure and health risk of local population via ingestion and dermal contact with water using deterministic and more robust probabilistic approach.

\section{Materials and methods}

\subsection{Water sampling and analytical procedures}

A total 105 water samples including surface water (60 samples) and ground water (45 samples) were collected for this study. Surface water samples (prefixed surface water [SW]) were collected from 20 sampling points from the study areas of Dhalaibeel $(n=30)$ and Bangshi River ( $\mathrm{n}=30$ ), up to a distance of $7.5 \mathrm{~km}$ from the DEPZ industrial area during monsoon season between June and July in 2015. Water samples from Dhalaibeel and Bangshi River were collected $250 \mathrm{~m}$ and $500 \mathrm{~m}$ apart, respectively, at same time interval. Groundwater samples from 15 tube wells (prefixed groundwater [GW]) around DEPZ industrial area were also collected (Fig. 1). Before the collection of groundwater samples, tube-wells were pumped for $5 \mathrm{~min}$ to wash out the stagnant water inside the tube-wells and to get fresh water. All samples were collected in plastic bottles following filtering through Whatman No. 541 filter paper. From each sampling point, three samples were taken in separate sampling bottles. The collected samples were acidified immediately with the addition of $2 \mathrm{ml}$ ultra-pure $\mathrm{HNO}_{3}$ per litre of water sample to stop microbial activities, shaken well and preserved in a refrigerator at $4^{\circ} \mathrm{C}$ before laboratory analysis (APHA, 1998).

Prior to analysis of heavy metals, the water samples were filtered through Whatman No. 541 filter paper into $100 \mathrm{~mL}$ pre-washed plastic bottles and the analytical grade $\mathrm{HCl}$ was used to adjust water $\mathrm{pH}$ to 3.5 . The concentrations of all heavy metals were determined by atomic absorption spectrophotometer (Model AA-6800, Shimadzu Corporation, Japan) in Nuclear Analytical Chemistry Laboratory, NRCD, Institute of Nuclear Science and Technology, Gonakbari, Savar. In order to check the measurement precision, standard reference solutions with a known concentration of the analysed metals were used as control 
samples. After every three samples, the control sample was analysed to check the accuracy of the analysis. Each sample was measured at least three times to check the reproducibility of the measurement. Samples were reanalysed if the relative standard deviation of the measurement exceeded $10 \%$.

\subsection{Data analysis and Monte Carlo simulation}

Uncertainty is pervasive in human health risk assessment due to the lack of precise knowledge, and the variability of environmental and individual human characteristics. In

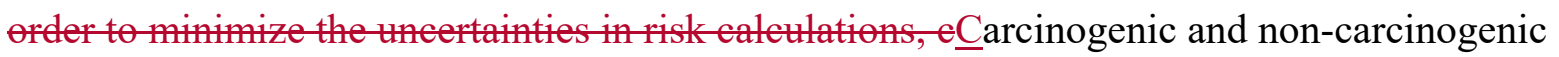
risks were quantified via Monte Carlo simulation performed by means of Oracle Crystal Ball (version 11). The software platform Oracle Crystal Ball is one of the most commonly used

Monte Carlo modelling tools. Monte Carlo simulation is a computer-based method of analysis that uses statistical sampling techniques in obtaining a probabilistic approximation to the solution of a mathematical equation or a model (Firestone et al., 1997; Thompson et al., 1992). The number of iterations for every equation was set at 10,000. The statistical and linear regression analysis was performed by SPSS (version 21) software.

\subsection{Human health risk assessment}

\subsubsection{Average daily dose (ADD)}

Human exposure to heavy metals may occur via three main pathways including direct ingestion, inhalation through the mouth and nose, and dermal absorption through exposed skin. For metals in a water environment, ingestion and dermal adsorption play the most important role. Considering these two pathways, the average daily dose was calculated using Equations (1) and (2) adapted from the US Environmental Protection Agency (Alves et al., 2014; USEPA, 1996). Calculations were performed for two subpopulation groups; adults (as the general population) and children (as a sensitive group) separately. 


$$
\mathrm{ADD}_{\text {ing }}=\frac{\mathrm{C}_{\mathrm{w}} \times \mathrm{IR} \times \mathrm{EF} \times \mathrm{ED}}{\mathrm{BW} \times \mathrm{AT}}
$$

$$
\mathrm{ADD}_{\text {derm }}=\frac{\mathrm{C}_{\mathrm{w}} \times \mathrm{SA} \times \mathrm{K}_{\mathrm{p}} \times \mathrm{EF} \times \mathrm{ED} \times \mathrm{ET} \times \mathrm{CF}}{\mathrm{BW} \times \mathrm{AT}}
$$

173 Where ADD represents average daily dose through ingestion (ADDing) and dermal absorption $174\left(\mathrm{ADD}_{\text {derm }}\right)\left(\mu \mathrm{g} \mathrm{kg}^{-1} \mathrm{day}^{-1}\right) ; \mathrm{C}_{\mathrm{w}}$ is the metal concentrations $\left(\mu \mathrm{g} \mathrm{L}^{-1}\right)$ in water; IR is the ingestion rate $\left(\right.$ day $\left.^{-1}\right)$ of water, EF \& ED are the exposure frequency (day year ${ }^{-1}$ ) and duration (year); BW is the body weight $(\mathrm{kg})$; AT is the averaging time (day); SA is the exposed skin surface area $\left(\mathrm{m}^{2}\right) ; \mathrm{K}_{\mathrm{p}}$ is the dermal permeability constant $\left(\mathrm{cm} \mathrm{h}^{-1}\right)$; ET is the exposure time $\left(\mathrm{h} \mathrm{day}{ }^{-1}\right)$; $\mathrm{CF}$ is the unit conversion factor $(=10)$.

The values and description of all the parameters used for deterministic and

probabilistic approaches are summarized in supplementary Table $\underline{\mathbf{S}} \mathbf{1}$. For the heavy metals in Bangshi River water with sample number $<15$, triangular distribution was assigned because concentrations of contaminants in the environment were frequently found to follow triangular distribution (Jiang et al., 2015). The probability distribution of the metals in the groundwater was determined by fitting distribution functions with the help of goodness-of-fit tests, which were Anderson-Darling (AD), Kolmogorov-Smirnov (KS), and chi-square (CS) tests (Kavcar et al., 2009). The Crystal ball software was used in fitting distribution. Table $\mathbf{S} \underline{\mathbf{2}} \mathbf{1}$ represents the analysed trace metals in the groundwater with fitted probability distributions, AD statistic values, and rank of the selected distribution by all three goodness-of-fit tests. The beta, exponential, gamma, normal, lognormal, logistic, pareto, and Weibull distributions were considered. $\mathrm{Pb}, \mathrm{Cd}$, and $\mathrm{Zn}$ concentrations in the groundwater were triangular, while $\mathrm{As}, \mathrm{Cu}$, and $\mathrm{Mn}$ were fitted to beta. $\mathrm{Ni}$ and $\mathrm{Cr}$ were fitted to pareto and Weibull distribution respectively (Table $\mathbf{S} \underline{\mathbf{2}} \mathbf{1})$.

\subsubsection{Non-carcinogenic risk}


194 The potential non-carcinogenic human health risks posed by heavy metal exposure are

195

196

197

198

199

200

201

202

203

204

205

206

207

208

209

210

211

212

213 usually characterized by the hazard quotient (HQ), which is the ratio of ADD of each contaminant for an individual exposure pathway (i.e., ingestion and dermal) to the corresponding reference dose $\left(\mathrm{RfD}\right.$, expressed in $\left.\mu \mathrm{g} \mathrm{kg}^{-1} \mathrm{day}^{-1}\right)$. The HQ was calculated using Equation (3) (USEPA, 2004).

$$
\mathrm{HQ}=\frac{\mathrm{ADD}}{\mathrm{RfD}}
$$

HQ is unit less and when its value exceeds 1 , there might be a concern for potential noncarcinogenic health risks associated with overexposure (USEPA, 2004).

In order to evaluate the total potential non-carcinogenic risks from more than one exposure pathway, the hazard index (HI) was introduced, which is the sum of HQs from all applicable pathways (De Miguel et al., 2007; Li and Zhang, 2010).

$$
\mathrm{HI}=\sum_{\mathrm{i}=1}^{\mathrm{n}} \mathrm{HQ}_{\mathrm{i}}
$$

Where $\mathrm{i}$ is the exposure pathway (ingestion and dermal are the two exposure routes of contaminants considered in this study). HI $>1$ indicates a potential for an adverse effect on human health or the necessity for further study (USEPA, 2004).

\subsubsection{Carcinogenic risk (CR)}

The carcinogenic risk is the unit less incremental probability of an individual developing cancer over a lifetime due to carcinogenic exposure. The carcinogenic risk was evaluated by Equation (5) (USEPA, 2004).

$$
\mathrm{CR}=\mathrm{ADD} \times \mathrm{CSF}
$$


214 Where ADD is the average daily dose (expressed in $\mu \mathrm{g} \mathrm{kg}^{-1}$ day $^{-1}$ ) and CSF is the cancer 215 slope factor (expressed in $\left[\mu \mathrm{g} \mathrm{kg}^{-1} \mathrm{day}^{-1}\right]^{-1}$ ). The cancer risk was evaluated for As, the only

216 element for which CSF values are available $\left(0.0015\right.$ and $0.00366\left[\mu_{\mathrm{g} \mathrm{kg}}^{-1} \mathrm{day}^{-1}\right]^{-1}$ for

217 ingestion and dermal, respectively) (De Miguel et al., 2007; Li and Zhang, 2010). The CR of 218 As was evaluated from the two exposure pathways (i.e., ingestion and dermal) and then the 219 values were summed to determine total carcinogenic risk (TCR). The range of carcinogenic risks acceptable or tolerable by the USEPA is $1 \times 10^{-6}$ to $1 \times 10^{-4}$. Risks surpassing $1 \times 10^{-4}$ are viewed as unacceptable while the risks below $1 \times 10^{-6}$ are not likely to pose significant health hazards.

\section{Results and discussion}

\subsection{Metal concentrations in ground and surface water}

The results obtained from the heavy metal analyses of the groundwater samples

227 around DEPZ and the surface water samples from Dhalaibeel and Bangshi River are graphically shown in Figs. 2 and 3, respectively, and are compared with the guideline values. The concentration data for 8 trace metals according to sampling locations are also summarized in supplementary Table $\mathbf{S} \underline{\mathbf{3}} \mathbf{t}$ and $\mathbf{S} \underline{\mathbf{4}} z$. The mean metal concentrations $\left(\mu \mathrm{g} \mathrm{L}^{-1}\right)$ in ground and surface water, respectively, followed a decreasing order as: $\mathrm{Zn}(127.63)>\mathrm{Cu}$ $(78.60)>\mathrm{Mn}(11.21)>\mathrm{Ni}(7.93)>\mathrm{Pb}(5.21)>\mathrm{Cr}(4.43)>\mathrm{As}(0.64)>\mathrm{Cd}(0.34)$ and $\mathrm{Zn}$ $(2623.34)>\mathrm{Cu}(1118.71)>\mathrm{Pb}(169.56)>\mathrm{Cr}(115.40)>\mathrm{Mn}(92.8)>\mathrm{Ni}(74.81)>\mathrm{As}(18.26)$ $>\mathrm{Cd}(8.21)$. In both cases, the highest concentrations were observed for $\mathrm{Zn}$ and $\mathrm{Cu}_{2}$ while the lowest for As and Cd. The trends in metal concentrations found in this study agreed with the trend observed in Pearl River water in China (Cheung et al., 2003) and also with the results reported by the Hong Kong Environmental Protection Department (EPD, 1995), where Zn and $\mathrm{Cu}$ were the most abundant and $\mathrm{Cd}$ was the least. The relatively high level of $\mathrm{Zn}$ and $\mathrm{Cu}$ 
found in this area may be attributed to the cumulative impact of numerous industries (e.g., printing, dyeing, leather, electroplating, various chemicals and metallurgical industries) and extensive use of fertilizers ${ }_{2}$ and $\mathrm{Cu}$ and $\mathrm{Zn}$-based pesticides in the agricultural lands (Alves et al., 2014; Cheung et al., 2003; Facchinelli et al., 2001; Sponza and Karaoğlu, 2002).

Increased accumulation of $\mathrm{Cu}$ and $\mathrm{Zn}$ in soils and their subsequent translocation into the adjacent water bodies may be related to the excess use of fertilizers, manures, and $\mathrm{Cu}$ and $\mathrm{Zn}$ based pesticides (Facehinelliet al., 2001). Similarly, higher acemmlation of Cu and Zn-were found in the water bodies next to industrial areas worldwide (Cheung et al., 2003; Sponza and Karaoğlu, 2002).

The Bangshi River is an important source of water for domestic uses, fisheries, and agriculture etc. Due to the higher cost of cultivation with groundwater, irrigation of the fields is primarily limited to waters derived from Bangshi River and Dhalaibeel. Therefore, the SW samples in Dhalaibeel and Bangshi River were compared with the irrigation water quality guidelines prescribed by Food and Agricultural Organisation (FAO) (Ayers and Westcot, 1994). The recorded concentrations were also compared with the long-term trigger values (LTV) and short-term trigger values (STV) for heavy metals in irrigation water suggested by Australia - New Zealand (ANWQG) (Anzecc, 2000) (Fig. 3). The LTV and STV refer the maximum concentration of contaminants in the irrigation water, which can be tolerated assuming 100 and 20 years, respectively, of irrigation. Figure 3 revealed that the median concentrations of $\mathrm{As}, \mathrm{Cd}, \mathrm{Mn}, \mathrm{Ni}$, and $\mathrm{Pb}$ were within the recommended limits suggested by FAO and LTV values, while $\mathrm{Cr}, \mathrm{Cu}$, and $\mathrm{Zn}$ exceeded the permissible limits. However, all the metal values were lower than the Australia - New Zealand recommended STV values.

Local residents also use the Bangshi River water for drinking purposes. The metal concentrations found in the river water samples were notable and exceeded the WHO (WHO, 2006) recommended levels except $\mathrm{Cu}, \mathrm{Mn}, \mathrm{Ni}$, and $\mathrm{Zn}$. Mean $\mathrm{Pb}$ concentration $\left(136.85 \mu \mathrm{g} \mathrm{\textrm {L } ^ { - }}\right.$ 
$264^{1}$ ) was $\sim 14$ times higher than the WHO provided guideline value $\left(10 \mu \mathrm{g} \mathrm{L}^{-1}\right)$. Whereas, the mean concentrations of $\mathrm{Cd}, \mathrm{Cr}$, and As were $\sim 2$ times higher than the respective WHO prescribed values. These high concentrations of hazardous metals ( $\mathrm{As}, \mathrm{Cd}, \mathrm{Cr}$, and $\mathrm{Pb}$ ) recorded in water samples may have serious human health implications (Bhowmick et al., 2015). The present values of the examined metals were higher than the values reported by Ahmed et al. (2012b) in and around DEPZ. However, our metal concentrations agreed well with the recently found values in DEPZ surface water by Rahman et al. (2014). In comparison with the Buriganga River in Bangladesh, $\mathrm{Pb}, \mathrm{Ni}$, and $\mathrm{Cu}$ concentrations were

272 several fold higher, while Cd and Cr concentrations were lower (Ahmad et al., 2010).

All the trace metals measured in the GW, which is used as the main source of drinking water by the local population, were below the WHO (WHO, 2006), USEPA (USEPA, 2012), and Bangladesh (ECR, 1997) recommended guideline values (Fig. 2), indicating no possible human health hazards. Our average concentrations of $\mathrm{Pb}, \mathrm{Cd}, \mathrm{Cu}, \mathrm{Mn}$, and Banu (2006) in the groundwater samples from the locations of north-west side of Dhalaibeel. The concentrations of $\mathrm{Ni}, \mathrm{Cr}$, and $\mathrm{Zn}$ found in this study were lower, $\mathrm{Cu}$ and $\mathrm{As}$ concentrations were $\sim 3$ fold higher, and $\mathrm{Pb}$ and $\mathrm{Cd}$ concentrations were similar to the values observed in shallow and deep tube wells water inside and around DEPZ by Ahmed et al. (2012a).

\subsection{Water contamination gradient at Dhalaibeel and Bangshi River}

The distribution of heavy metals in SW displayed a large spatial variation with higher concentration close to DEPZ industrial areas (Fig. 4). A significant decrease in metal concentrations with increasing distance from the DEPZ industrial zone was observed in Fig. the discharge of untreated industrial effluents into the Dhalaibeel, which migrated along the 
Bangshi River hydrological gradients. In addition, surface runoff from the agricultural land could bring excess trace metals into nearby water environment. However, the decrease in metal concentration as a function of distance from DEPZ due to the downward dilution effect of metal-bearing industrial effluents is an indication of industrial pollution for these elements in surface water. Significant decreasing trends in metal levels with distance from Aliga metal industry district in Turkey was also reported by Sponza and Karaoğlu (2002). Some exceptions with no apparent concentration gradient were observed in this study. For example, fluctuation in As concentrations did not follow any statistically significant trend $($ As $=18.27$ $-0.0002 \times$ distance from DPEZ; $\left.\mathrm{R}^{2}=0.00\right)($ Fig. 4b). Although a linearly decreasing trend in Mn concentration was observed, statistically this relationship was very weak $(\mathrm{Mn}=101.12-$ $2.51 \times$ distance from DEPZ; $\left.\mathrm{R}^{2}=0.11\right)($ Fig. $4 d) . \underline{\text { In order to understand the reason for such }}$ exception, surface water data set were subjected to principal component analysis (PCA)

(Table S5). The PCA result identified two principal components (PCs) that played a critical role in explaining metal contamination in the surface water. PC1 and PC2 explained 46.5\% and $21 \%$ of the total variance, respectively. $\mathrm{PC} 1$ was loaded heavily on $\mathrm{Cd}, \mathrm{Cr}, \mathrm{Cu}, \mathrm{Ni}, \mathrm{Pb}$, and $\mathrm{Zn}$, and could represent industrial sources. On the other hand, PC2 was loaded on As and $\underline{\mathrm{Mn}, \text { and can be explained as natural (geogenic) sources. Natural origin of these two metals in }}$ the studied surface water could be the reason of showing no apparent concentration gradient

307 from the DEPZ industries.

\subsection{Human health risk assessment}

\subsubsection{Average daily dose}

The heavy metal concentrations measured in the Bangshi River water and groundwater samples were used to assess the average daily dose (ADD) through ingestion and dermal contact. Two population groups (i.e., adult and children) were considered throughout the analyses. Adult and children exposure and risk assessments were carried out by both 
deterministic and probabilistic approaches for the eight analysed heavy metals. The deterministically and probabilistically estimated ADD values (mean, median, 5th, and 95th percentile) for adult and children through ingestion and dermal contact of SW and GW are summarized in Table $\mathbf{2} \underline{\mathbf{S 6}}$ and $\mathbf{3} \underline{\mathbf{S} 7}$. However, some of the highest model values from probabilistic approach might be overestimation and consequently, it has been suggested to use the 95th percentile values as high-end estimates instead of the maxima (Kavcar et al., 2009). In this study, 5th percentile and 95th percentile were considered as the low - and high - end estimates for probabilistic and deterministic risk calculations. Although the mean ADD values calculated by deterministic and probabilistic approaches were pretty same, the range of variation of ADD values estimated by probabilistic approach was higher than the deterministic approach. For example, probabilistically calculated 95th percentile ADD values for adult through ingestion of SW and GW were $\sim 4$ times higher than the values calculated deterministically. Whereas the probabilistic estimates of 5th percentile ADD values were 15 times less than that calculated by the deterministic approach.

With regard to the different exposure routes of water, ingestion played the dominant role in total ADD (ingestion and dermal combined) for all the metal analysed as reported by many other studies (Alves et al., 2014). In comparison to dermal contact, the estimated ADD values through ingestion were $\sim 2$ to 3 orders of magnitude higher, indicating human exposure to heavy metals through dermal contact of water was negligible (Table $\mathbf{2} \underline{\mathbf{S 6}}$ and 3S7). Moreover, a big difference between ADD values for SW and GW was observed due to higher metal content in SW relative to GW. Human exposure (ingestion and dermal combined) to heavy metals through Bangshi River SW was $\sim 5$ to $\sim 30$ times higher than through the GW. Between two different exposure groups, deterministic estimation of mean ADD values showed that children were $\sim 1.7$ times more exposed to SW as well as GW than adult. On the other hand, probabilistically calculated mean ADD values for adult and children 
339 were pretty similar (Table $\mathbf{2} \underline{\mathbf{S 6}}$ and $\mathbf{3 S 7}$ ). Among all of the investigated heavy metals, adult and children were most exposed to $\mathrm{Zn}$ and $\mathrm{Cu}$ because of their higher concentrations in the

$341 \mathrm{SW}$ and GW, while the people in the present study area were least exposed to Cd (Table $2 \underline{\mathbf{S 6}}$ 342 and 3 7 $)$. For instance, the probabilistic mean $\mathrm{ADD}$ values of $\mathrm{Zn}$ and $\mathrm{Cu}$ for adult through SW ingestion reached at $1.07 \mathrm{E}+02$ and $4.64 \mathrm{E}+01 \mu \mathrm{g} \mathrm{kg}^{-1}$ day ${ }^{-1}$, respectively. In contrast, respective mean ADD value for Cd was 3.59E- $01 \mu \mathrm{g} \mathrm{kg}^{-1}$ day $^{-1}$, representing $0.3 \%$ and $0.8 \%$ of the exposure to $\mathrm{Zn}$ and $\mathrm{Cu}$, respectively.

\subsubsection{Hazard quotient}

Deterministic and probabilistic estimates of HQ for eight trace metals in Bangshi

348 River and groundwater through exposure to ingestion and dermal contact for-with adult and

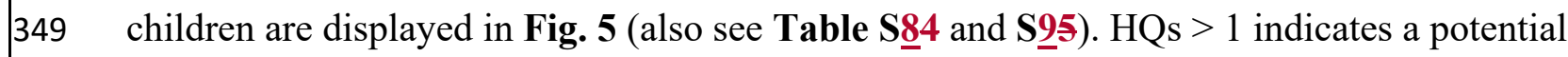
350 for a non-carcinogenic adverse health effect to occur or the need for further study. For 351 Bangshi River $\mathrm{SW}$ ingestion, the mean $\mathrm{HQ}$ values of $\mathrm{As}, \mathrm{Cr}, \mathrm{Cu}_{2}$ and $\mathrm{Pb}$ exceeded the respective safe reference doses (i.e., HQs $>1$ ) for adult as well as children (Fig. 5a). For the exposed population to $\mathrm{SW}, \mathrm{Pb}$ and As contributed the most to total HQs followed by $\mathrm{Cr}, \mathrm{Cu}$, and $\mathrm{Cd}$. Rest of the metals (i.e., $\mathrm{Ni}, \mathrm{Zn}$, and $\mathrm{Mn}$ ) had a minimum contribution on the total HQs (Fig. 5a). Although Zn was characterized by the highest ADD value, it posed a least non-carcinogenic risk due to its relatively high reference dose value. Considering the dermal pathway of SW, mean HQs values of all the metals were below the safety level (i.e., HQs < 1) (Fig. 5b). However, the probabilistic estimates of dermal HQ for $\mathrm{Cr}$ ranged from 0.02 to for adult and children by probabilistic and deterministic approaches through ingestion and dermal contact were less than 1.0 (Fig. 5c and 5d), indicating no possible health threat for human in terms of groundwater intake in the present study area. 

and children ranged from 1.22 to 1.44 and 0.73 to 0.85 , respectively, for the analysed heavy metals. According to this study, the range of variability of HQ values estimated probabilistically was higher than the values determined deterministically. For example, probabilistically estimated 95th percentile HQ values of metals for adults and children were 3.38 to 4.1 and 1.64 to 2.05 , respectively, times greater than the values calculated deterministically. On the other hand, probabilistic/ deterministic ratios of 5th percentile HQ values for adults ranged from 0.01 to 0.09 , whereas for children ranged from 3.38 to 4.31 . This indicates that the probabilistic approach covers all the possible scenarios including extremes, which might not be encountered by the deterministic approach.

\subsubsection{Hazard index}

The non-carcinogenic risk associated with the combined ingestion and dermal exposure to As, $\mathrm{Cr}, \mathrm{Cu}$, and $\mathrm{Pb}$ exceeded the safety level $(\mathrm{HI}>1.0)$ for adult and children at the Bangshi River area (Fig. 6a and Table S106). The mean HI values of Cd were in the line of benchmark value of 1.0 (Fig. 6a). Lead exhibited the highest value of $\mathrm{HI}$ for adult (varied from 2.09 to 4.39 with a mean value of 3.28 for deterministic calculation, while varied from $\theta .15$ to 17.4 with a mean value of 4.67 for probabilistic calculation) and children (varied from 3.45 to 7.25 with a mean value of 5.41 for deterministic calculation, while varied from 0.62 to 13.6 with a mean value of 4.64 for probabilistic calculation) followed by $\mathrm{As}, \mathrm{Cr}, \mathrm{Cu}, \mathrm{Cd}$, $\mathrm{Zn}, \mathrm{Mn}$, and $\mathrm{Ni}$ (Fig. 6a). Only a minor contribution ( $<1 \%$ for $\mathrm{As}, \mathrm{Zn}, \mathrm{Cu}, \mathrm{Ni}$, and $\mathrm{Pb} ; \sim 5 \%$ for $\mathrm{Mn} ; \sim 19 \%$ for $\mathrm{Cd} ; \sim 33 \%$ for $\mathrm{Cr}$ ) of the dermal pathway on $\mathrm{HI}$ of the analysed metals was observed in this study. However, the HI values for all the metals in groundwater for adult and children were less than 1.0 (Fig. 6b), giving no possible indication of human health hazards. Furthermore, it is noteworthy to state that the deterministic HI of children was 
non-carcinogenic risk from the heavy metals. However no significant difference between children and adults HI were observed for simulation results (Fig. 6 and Table S106).

\subsubsection{Ingestion, dermal and total cancer risk (TCR)}

To date, oral and dermal slope factors have been derived only for As. Consequently, the risk of cancer for adult and children due to ingestion and dermal exposure to surface and groundwater were only estimated for As by the deterministic and probabilistic approach and graphically shown in Fig. 7 (also see Table S117). There is no uniform carcinogenic risk standard. Although the most commonly considered cancer risk level is 1 -in-1,000,000 (i.e., 1 $\left.\times 10^{-6}\right)$, this level may change to 1 -in-10,000 $\left(1 \times 10^{-4}\right)$ according to national standards and environmental policies (USEPA, 2012). Thus, the generally considered acceptable range of cancer risk is $1 \times 10^{-6}$ to $1 \times 10^{-4}$. This study also considered the higher end (i.e., $1 \times 10^{-4}$ ) of the carcinogenic risk as unacceptable, exceedance of which may pose detrimental health hazards to exposed population.

Considering both exposure pathways of SW, deterministically estimated TCR for adult ranged from 1.91E-04 to 5.31E-04, while that for children was between $6.31 \mathrm{E}-05$ and 1.75E-04. On the other hand, the probabilistically estimated TCR was in the range of $6.18 \mathrm{E}-$ 06 to 2.42E-04 for adult and between 7.20E-06 and 1.01E-04 for children (Fig. 7a).

Deterministic mean TCR for adult and children exceeded the safety limit of $1 \times 10^{-4}$ (Fig. 7a). For adult, even the 5th percentile deterministic value (1.91E-04) was $\sim 2$ times and 95th percentile value was $\sim 5$ times higher than the upper recommended limit (Fig. 7a). Conversely, the probabilistic mean TCR for adult and children were less than $1 \times 10^{-4}$ (although 95th percentile TCR values exceeded the upper benchmark) (Fig. 7a). In this study, probabilistic simulation for SW showed that $20.13 \%$ TCR values for adult and $5.43 \%$ TCR values for children were $>1 \times 10^{-4}$. On the other hand, deterministic estimation seems to over 
412 predict the TCR calculation with $100 \%$ and $80 \%$ of TCR values $>1 \times 10^{-4}$ for adult and 413 children, respectively. For GW deterministic estimates for TCR varied from 1.14E-04 to 1.70E-05 for adult

415

416

417 and from $3.76 \mathrm{E}-06$ to $5.61 \mathrm{E}-06$ for children. On the contrary, the probabilistic estimate ranged from 2.65E-07 and 9.77E-06 for adult and between 3.12E-07 and 3.98E-06 for children (Fig. 7b). Our results showed that TCR through exposure to GW around DEPZ was well below $1 \times 10^{-4}$ for adult and children estimated by two different approaches (i.e., deterministic and probabilistic) (Fig. 7b), meaning that local population can safely drink groundwater.

Overall, our results showed that population exposed to Bangshi River water remained at high cancer risk and this risk was higher for adults relative to children due to exposure to the surface as well as groundwater. With regard to different exposure pathways, the dermal route contributed very little $(<1 \%)$ to the total cancer risk.

\subsubsection{Sensitivity and uncertainty analysis}

Sensitivity analysis was performed to identify input variables that contribute most significantly to the probabilistic non-carcinogenic and carcinogenic risk estimation. The results of sensitivity analysis showed that exposure duration (ED) and ingestion rate (IR) were the two most influential variables to surface and groundwater HI and TCR for both adult and children (Fig. A1 and A2).

Uncertainty analysis for the simulated HI (surface and groundwater) and TCR was conducted using the boot-strapping method. The results of uncertainty analysis are presented in Table S $\underline{128}$, S $\underline{13} 9$, and S1 $\underline{4} \theta$. Environmental managers and policy makers would be better 
equipped with these ranges in decision making. It should be pointed out that in conjunction

436

437

438

439

440

441

442

with the quantified uncertainty of the simulated results, there are some other uncertainties that could not be quantified and may be a limit to the validity of the case presented. For example, (i) seasonal variation of trace metals were not investigated, (ii) daily intake of water and body weights were acquired not measured, (iii) most of the probability distributions used for simulation were based on the USEPA data, (iv) uncertainty in the best fitted distribution, (v) CSF was treated as a constant for all members of the population, but in reality it can vary from person to person, (vi) total metal concentrations found in the water samples were considered as bioavailable concentration in human body that could somewhat overestimate the risk assessment, and (vii) metal speciation is important for more robust health risk estimation because the metal occurs as different species and exhibits different toxicity. Although the risk assessments in this study may not provide an absolutely accurate scenario of human health hazards, this study provides a preliminary investigation of health risk of heavy metals to local adult and children in the vicinity of DEPZ.

\section{Conclusion}

This study found that among eight heavy metals, $\mathrm{Zn}$ and $\mathrm{Cu}$ represented the highest mean concentrations in both surface and groundwater, while As and Cd concentrations were the least. A S S ignificant decrease in metal concentration (except As and Mn) with distance from the $\underline{\mathrm{DEPZ}}$ industrial area was observed in surface water, which was an indicationcan be attributed to ef industrial metal pollution to nearby water bodies. With a few exception $(\mathrm{Cr}$, $\mathrm{Cu}$, and $\mathrm{Zn}), \mathrm{SW}$ metal concentrations were within the recommended limits for irrigation purposes. The current results exhibited that four toxic metals (i.e., $\mathrm{As}, \mathrm{Cd}, \mathrm{Cr}$, and $\mathrm{Pb}$ ) in Bangshi River water exceeded the WHO recommended limit for drinking water, whereas, metals in groundwater samples were well within the WHO prescribed limits. 
$460 \quad$ The potential of exposure and human risk-assessments study were-found that

461 population around DEPZ industrial were more exposed to $\mathrm{Zn}$ and $\mathrm{Cu}$ in Bangshi River water

462 and ingestion was the dominant pathway of metal exposuredue to mostly ingestion of water

463 from the Bangshi River. Human health risk assessment indicated that ingestion of Bangshi

464 River water Thus it can be a better is a matter of great concern for the local residents due to

465 non-cancer risk from $\mathrm{As}, \mathrm{Cr}, \mathrm{Cu}$, and $\mathrm{Pb}_{2}$ and carcinogenic risk from As. This study identified

$466 \mathrm{As}, \mathrm{Cr}, \mathrm{Cu}$, and $\mathrm{Pb}$ as priority pollutants that calls for further attention and investigation. Both

467 Carcinogenic and non-carcinogenic risks throughassociated with dermal contact could be

ignored. However, the groundwater was identified as safe for human consumption by both

469 deterministic and probabilistic approaches but can be critical due to increasing industrial

470 activities. Thus surface and groundwater around this rapidly increasing industrial area should

471 keep under continuous investigation. In addition, sensitivity analysis showed thatidentified

472 exposure duration (ED) and ingestion rate (IR) of water were-as two most important variables

473 for probabilistic health risk estimation.

Finally, reliance on unprotected and untreated industrial water for irrigation and

475 drinking purposes put the local population at risk of chemical contamination. regulations on

the overuse of agrochemicals and water treatment technologies should be taken into account

to Bangshi River water. Improved and continuous environmental monitoring, industry

$\underline{\text { transparency, construction and proper use of waste water treatment plants, and new }}$

regulatory initiatives including substantial fines and criminal penalties could help to resolve

480 industrial contamination of surface water and to reduce human health risks. In order to

481 improve the environmental condition, policy makers should emphasis on management of

482 environmental and human health risks, without considering industrial and associated economic growth as single most important policy objective. 
485 The authors are grateful for the laboratory facilities from Bangladesh Atomic Energy

486 Commission for analysing water samples.

\section{Conflict of interests}

488 The author declares that there is not conflict of interest.

489

490

\section{References}

491

492

493

494

495

496

497

498

499

500

501

502

503

504

505

506

507

Ahmad M., Islam S., Rahman M., Haque M., Islam M., 2010. Heavy metals in water, sediment and some fishes of Buriganga River, Bangladesh. Int. J. Environ. Res. 4: 321-332.

Ahmed G., Anwar H.M., Chowdhury D.A., Ahmed J.U., Khan M.A., Hoque S., 2012a. Pollution Status of Trace Metals in Groundwater Due to Industrial Activities in and Around Dhaka Export Processing Zone, Bangladesh. Int. J. Econ. Environ. Geol. 3: 43-52.

Ahmed G., Miah M.A., Anawar H.M., Chowdhury D.A., Ahmad J.U.,2012b. Influence of multi-industrial activities on trace metal contamination: an approach towards surface water body in the vicinity of Dhaka Export Processing Zone (DEPZ). Environ. Monit. Assess. 184: 4181-4190.

Alves R.I., Sampaio C.F., Nadal M., Schuhmacher M., Domingo J.L., Segura-Muñoz S.I., 2014. Metal concentrations in surface water and sediments from Pardo River, Brazil: Human health risks. Environ. Res.133: 149-155.

Amaya, E., Gil, F., Freire, C., Olmedo, P., Fernandez-Rodriguez, M., Fernandez, M.F. and Olea, N., 2013. Placental concentrations of heavy metals in a mother-child cohort. Environ. Res. 120, 63-70. 
Anzecc A. 2000. Australian and New Zealand guidelines for fresh and marine water quality. Australian and New Zealand Environment and Conservation Council and Agriculture and Resource Management Council of Australia and New Zealand, Canberra. 1-103.

APHA. 1998. Standard methods for the examination of water and wastewater. American Public Health Association, American Water Works Association and Water Environment Federation, Washington, DC.

Armendáriz, C.R., Garcia, T., Soler, A., Fernández, Á.J.G., Glez-Weller, D., González, G.L., de la Torre, A.H. and Gironés, C.R., 2015. Heavy metals in cigarettes for sale in Spain. Environ. Res. 143, 162-169.

Ayers R. and Westcot D. 1994. Water quality for agriculture. FAO Irrigation and drainage paper 29 Rev. 1. Food and Agricultural Organization. Rome.

Biswas R. and Banu R., 2006. A study on the ground water quality around Dhalai Beel area adjacent of Dhaka export processing zone. Curr. World Environ. 1: 133-138.

Bhowmick, S., Kundu, A.K., Adhikari, J., Chatterjee, D., Iglesias, M., Nriagu, J., Mazumder, D.N.G., Shomar, B. and Chatterjee, D., 2015. Assessment of toxic metals in groundwater and saliva in an arsenic affected area of West Bengal, India: A pilot scale study. Environ. Res. 142.328-336.

Cheung K., Poon B., Lan C., Wong M., 2003. Assessment of metal and nutrient concentrations in river water and sediment collected from the cities in the Pearl River Delta, South China. Chemosphere 52: 1431-1440.

De Miguel E., Iribarren I., Chacon E., Ordonez A., Charlesworth S., 2007. Risk-based evaluation of the exposure of children to trace elements in playgrounds in Madrid (Spain). Chemosphere 66: 505-513.

ECR. The Environment Conservation Rules, Government of the People's Republic of Bangladesh, Ministry of Environment and Forest, Bangladesh, 1997. 
EPD. 1995. Environment Hong Kong. Hong Kong Environmental Protection Department, Hong Kong.

Espín, S., Martínez-López, E., Jiménez, P., María-Mojica, P. and García-Fernández, A.J., 2014. Effects of heavy metals on biomarkers for oxidative stress in Griffon vulture (Gyps fulvus). Environ. Res., 129, 59-68.

Facchinelli A., Sacchi E., Mallen L., 2001. Multivariate statistical and GIS-based approach to identify heavy metal sources in soils. Environ. Pollut. 114: 313-324.

Firestone M., Fenner-Crisp P., Barry T., Bennett D., Chang S., Callahan M. 1997. Guiding principles for Monte Carlo analysis. Risk Assessment Forum, US Environmental Protection Agency Washington, DC.

Giri, S., Singh, A. K., 2015. Human health risk assessment via drinking water pathway due to metal contamination in the groundwater of Subarnarekha River Basin, India. Environ. Monit. Assess. 187, 1-14.

Islam M.S., Ahmed M.K., Habibullah-Al-Mamun M., 2015. Determination of heavy metals in fish and vegetables in Bangladesh and health implications. Human Ecol. Risk Assess. An Int. J. 21 (4): 986-1006.

Jiang Y., Zeng X., Fan X., Chao S., Zhu M., Cao H., 2015. Levels of arsenic pollution in daily foodstuffs and soils and its associated human health risk in a town in Jiangsu Province, China. Ecotoxicol. Environ. Saf. 122: 198-204.

Kavcar P., Sofuoglu A., Sofuoglu S.C., 2009. A health risk assessment for exposure to trace metals via drinking water ingestion pathway. Int. J. Hyg. Environ. Health 212: 216227.

Koupaie, E.H., Eskicioglu, C., 2015. Health risk assessment of heavy metals through the consumption of food crops fertilized by biosolids: A probabilistic-based analysis. J. Hazard. Mater. 300: 855-865. 
Li S. and Zhang Q., 2010. Risk assessment and seasonal variations of dissolved trace elements and heavy metals in the Upper Han River, China. J. Hazar. Mater. 181: 1051-1058.

Mainali B., Pham T.T.N., Ngo H.H., Guo W., 2013. Maximum allowable values of the heavy metals in recycled water for household laundry. Sci. Total Environ. 452: 427-432.

Quandt, S.A., Jones, B.T., Talton, J.W., Whalley, L.E., Galván, L., Vallejos, Q.M., Grzywacz, J.G., Chen, H., Pharr, K.E., Isom, S. and Arcury, T.A., 2010. Heavy metals exposures among Mexican farmworkers in eastern North Carolina. Environ. Res., 110(1), 83-88.

Qu C.S., Ma Z.W., Yang J., Liu Y., Bi J., Huang L., 2012. Human exposure pathways of heavy metals in a lead-zinc mining area, Jiangsu Province, China. PloS One. 7(11): 46793.

Rahman M.S., Molla A.H., Saha N., Rahman A., 2012a. Study on heavy metals levels and its risk assessment in some edible fishes from Bangshi River, Savar, Dhaka, Bangladesh. Food Chem. 134: 1847-1854.

Rahman M.S., Saha N., Molla A.H., 2014. Potential ecological risk assessment of heavy metal contamination in sediment and water body around Dhaka export processing zone, Bangladesh. Environ. Earth Sci. 71: 2293-2308.

Rahman S.H., Khanam D., Adyel T.M., Islam M.S., Ahsan M.A., Akbor M.A., $2012 b$. Assessment of heavy metal contamination of agricultural soil around Dhaka Export Processing Zone (DEPZ), Bangladesh: Implication of seasonal variation and indices. Appl. Sci. 2: 584-601.

Razak, F., Corsi, D. J., Subramanian, S., 2013. Change in the body mass index distribution for women: analysis of surveys from 37 low-and middle-income countries. PLoS medicine. 10, e1001367. 
Rivera-Velasquez M.F., Fallico C., Guerra I., Straface S., 2013. A Comparison of deterministic and probabilistic approaches for assessing risks from contaminated aquifers: An Italian case study. Waste Manag. Res. 31: 1245-1254.

Saha N., Rahman M.S., Jolly Y., Rahman A., Sattar M.A., Hai M.A., 2016. Spatial distribution and contamination assessment of six heavy metals in soils and their transfer into mature tobacco plants in Kushtia District, Bangladesh. Environ. Sci. Pollut. Res. 23: 3414-3426.

Saha N. and Zaman M., 2013. Evaluation of possible health risks of heavy metals by consumption of foodstuffs available in the central market of Rajshahi City, Bangladesh. Environ. Monit. Assess. 185: 3867-3878.

Sponza D. and Karaoğlu N., 2002. Environmental geochemistry and pollution studies of Aliağa metal industry district. Environ. Int. 27: 541-553.

Thompson K.M., Burmaster D.E., Crouch E.A., 1992. Mlonte Carlo Techniques for Quantitative Uncertainty Analysis in Public Health Risk Assessments. Risk Anal.1992; 12 (1): 53-63.

USEPA, Risk Assessment Guidance for Superfund. Volume I: Human Health Evaluation Manual (Part A). US Environmental Protection Agency, Washington, DC, 1989.

USEPA. 1996. Quantitative Uncertainty Analysis of Superfund Residential Risk Pathway Models for Soil and Groundwater: White Paper. US Environmental Protection Agency, USA.

USEPA. 2004. Risk Assessment Guidance for Superfund Volume I: Human Health Evaluation Manual (Part E, Supplemental Guidance for Dermal Risk Assessment). US Environment Protection Agency, Washington DC.

USEPA. 2012. Edition of the Drinking Water Standards and Health Advisories. U. S. Environmental Protection Agency, Washington, DC. 
608 WHO. Guidelines for Drinking-water Quality, $3^{\text {rd }}$ Edition, Geneva; 2006.

609 Zeng, G., Liang, J., Guo, S., Shi, L., Xiang, L., Li, X., Du, C., 2009. Spatial analysis of

610 human health risk associated with ingesting manganese in Huangxing Town, Middle

$611 \quad$ China. Chemosphere. 77, 368-375.

612 Wyatt, C.J., Fimbres, C., Romo, L., Mendez, R.O. and Grijalva, M., 1998. Incidence of heavy 613 metal contamination in water supplies in Northern Mexico. Environ. Res., 76(2), 114$614 \quad 119$.

615 